\title{
PREPARATION AND PROPERTIES OF MAGNETIC CELLULOSE FIBER COMPOSITES
}

\author{
Wei-Bing Wu,,${ }^{\mathrm{a}, \mathrm{b}, *}$ Yi Jing, ${ }^{\mathrm{a}}$ Mu-Rong Gong, ${ }^{\mathrm{a}}$ Xiao-Fan Zhou, ${ }^{\mathrm{a}}$ and Hong-Qi Dai ${ }^{\mathrm{a}}$
}

\begin{abstract}
Magnetic cellulose fiber composites were prepared by a "vacuum-lumenloading" method with polyethylenimine (PEI) as retention aid. The composites thus formed preserved the inherent properties of the cellulose fiber and gained the magnetically responsive properties of nanoparticles. Magnetic paper was further made from the composites. These materials were characterized by X-ray diffraction, transmission electron microscopy, scanning electron microscopy, a vibrating sample magnetometer, and paper testers. There was a large amount of magnetic nanoparticles deposited on the exterior, in the pores, and especially in the lumen of fibers. Lumen loading of nanoparticles is favored by pulp beating, silica shell modification of magnetite, vacuum conditioning, and usage of PEI. The physical strength of paper was reduced to a certain extent because of unavoidable deposition of nanoparticles on the exterior of fibers, which could block the formation of hydrogen bonding between fibers. Our results show that both the cellulose fiber composites and the resulting paper possessed good superparamagnetism with tiny remnant magnetization and coercivity. These materials will allow the investigation of new concepts in paper making and packaging, security paper, and information storage.
\end{abstract}

Keywords: Composites; Silica core-shell nanoparticles; Cellulose fiber; Lumen loading; Magnetic paper

Contact information: a: Jiangsu Provincial Key Lab of Pulp and Paper Science and Technology, Nanjing Forestry University, Nanjing, 210037, China; b: State Key Lab of Pulp and Paper Engineering, South China University of Technology, Guangzhou, 510641, China *Corresponding author: wbwu@yahoo.cn

\section{INTRODUCTION}

Composite materials have attracted more and more attention due to the potential synergistic properties that may arise from the combination of two or more precursors. Recently, increasing research interest has been devoted to cellulose-based composite materials, since cellulose is renewable and the most abundant natural resource on Earth. By incorporating specific fillers, cellulose fiber can take on conductive (Johnston et al. 2006), photoluminescent (Sarrazin et al. 2007; Khan and Sundararajan 2011), catalytic (Fukahori et al. 2007), antimicrobial (Qian et al. 2009; Roy et al. 2008), or flameretardant properties (Basta et al. 2002; Bakirtzis et al. 2009), which open the doors to myriad new potential applications. Magnetic cellulose fiber composites, which exhibit the inherent properties of cellulose fiber substrate and also the magnetically responsive properties of the bonded nanoparticles, are of particular interest due to their potential applications in security paper, information storage, electromagnetic shielding, magnetographic printing, and magnetic filtering (Marchessault et al. 1992; CarrazanaGarcia et al. 1995; Small and Johnston 2009). However, relatively little research attention 
has been focused on it.

Throughout the literature, "in situ" synthesis (Raymond et al. 1994; CarrazanaGarcia et al. 1997; Suber et al. 2001; Chia et al. 2008) and the "lumen-loading" approach (Middleton and Scallan 1985; Marchessault et al. 1992; Zakaria et al. 2004a, 2004b; Mancosky and Lucia 2005; Kumar et al. 2011) are the main reported methods to prepare magnetic cellulose composites. While attempting to produce composites with multiple functionalities, one challenge that arises is that often the enhancement of one property comes at the cost of another. "In situ" synthesis is a loading method that relies on chemical formation and deposition of magnetic nanoparticles. The method cannot eliminate some intrinsic disadvantages such as rigorous reaction conditions, bad control of deposition location, unstable composition of magnetic nanoparticles, and low tensile strength of paper. "Lumen-loading" approach is a physical deposition process, as is the case of the retention of filler in papermaking. As opposed to "in situ" synthesis, it possesses advantages as follows: Protection of loaded magnetic nanoparticles by the cell wall from dislodgement during subsequent handling, a multiplicity of choices of loading materials, and exposed cellulose surface for interfiber bonding or further modification, among others. However, the 'lumen-loading' approach is still necessary to diminish the poor retention of the inorganic particles and the loss of mechanical strength of the fibers (Middleton et al. 1985; Zakaria et al. 2004a; Shen et al. 2011).

In this paper, we report a modified "lumen-loading" method, in which silica coreshell magnetic nanoparticles were chosen as filler and the loading process was conducted under vacuum to enhance the deposition of nanoparticles in the fiber lumen. Kraft pulp fibers, which are delignified, separated wood cells with a length of 3 to $5 \mathrm{~mm}$ and a diameter of 20 to $40 \mu \mathrm{m}$, were used as cellulose substrates. Their lumens are natural containers to incorporate nanoparticles. Usually, the fibers are negatively charged (Eriksson et al. 2005; Zheng et al. 2006). So it is possible to apply electric charge interaction to improve the retention efficiency of nanoparticles. The kinetics and mechanism of filler deposition in lumen of cellulose fiber were also studied.

\section{EXPERIMENTAL}

\section{Materials}

$\mathrm{FeCl}_{3} \cdot 6 \mathrm{H}_{2} \mathrm{O}, \mathrm{FeCl}_{2} \cdot 4 \mathrm{H}_{2} \mathrm{O}$, tetraethoxysilane (TEOS, 98.6\%), $\mathrm{Al}_{2}\left(\mathrm{SO}_{4}\right)_{3}$, and $\mathrm{NH}_{3} \cdot \mathrm{H}_{2} \mathrm{O}$ solution (25 to $28 \%$ ) were of chemical grade and purchased from Sinopharm Group Chemical Reagent Ltd. They were used directly without further purification. Polyethylenimine (PEI) solution (40 wt \%) with molecular weight of 1,000 to 5,000 was purchased from Jiangsu Mengde Electroplate Products Co., Ltd.. Suspensions and solutions were prepared using distilled water. Bleached softwood kraft pulp was supplied by a pulp mill.

\section{Preparation of Silica Core-Shell Magnetic Nanoparticles}

Magnetic nanoparticles were prepared, purified, and modified with citric acid according to the literature (Sun et al. 2005). The modified nanoparticles were diluted to 2 $\mathrm{mg} / \mathrm{mL}$ by $95 \%$ ethanol and ultrasonically dispersed for $30 \mathrm{~min}$. To above suspension 
$(100 \mathrm{~mL}), 0.45 \mathrm{wt} \%$ sodium-silicate solution $(1.2 \mathrm{~mL})$ was added to the ethanol under vigorous mechanical stirring. After $4 \mathrm{~h}, \mathrm{NH}_{3} \cdot \mathrm{H}_{2} \mathrm{O}(9 \mathrm{~mL})$ and TEOS $(2.5 \mathrm{~mL})$ solution were added consecutively in half hour. After reaction for $10 \mathrm{~h}$, products were precipitated under magnetic field. They were redispersed in distilled water and precipitated again by magnetic separation. Above procedure were repeated several times until the $\mathrm{pH}$ was 7 .

\section{Preparation of Magnetic Composites}

Conventional "lumen-loading" method

Softwood kraft pulp was previously beaten to desired beating degree according to TAPPI method T200 sp-01 (TAPPI 2001a). Pulp samples (8 g, oven-dried weight) were dispersed in $0.1 \mathrm{~g} / \mathrm{L} \mathrm{Al}_{2}\left(\mathrm{SO}_{4}\right)_{3}(800 \mathrm{~mL})$ aqueous solution under stirring for approximately $30 \mathrm{~min}$. Then $10 \mathrm{mg} / \mathrm{mL}$ nanoparticle suspension $(400 \mathrm{ml})$ was added to the above pulp suspension and stirred at the rate of $1000 \mathrm{rpm}$ for $1 \mathrm{~h}$, after which PEI was added and the suspension was continuously stirred at the rate of $300 \mathrm{rpm}$ for $4 \mathrm{~h}$. Afterwards, the products were ultrasonicated for $20 \mathrm{~min}$, filtered in a 325-mesh sieve, and extensively washed with water. The obtained black fibers were further used to make paper sheet in accordance with TAPPI method T205 sp-02 (TAPPI 2002).

\section{"Vacuum lumen-loading" method}

Softwood kraft pulp with desired beating degree was previously swollen and disintegrated in water. Then the pulp suspension was filtered and vacuum freezing dried for $72 \mathrm{~h}$. Oven dried pulp ( $8 \mathrm{~g}$ ) were placed in a four-neck flask equipped with constant funnel. When the flask was pumped to $10 \mathrm{mmHg}, 0.1 \mathrm{~g} / \mathrm{L} \mathrm{Al} \mathrm{Al}_{2}\left(\mathrm{SO}_{4}\right)_{3}(800 \mathrm{~mL})$ aqueous solution was added and magnetically stirred for approximately $30 \mathrm{~min}$. Afterwards, 10 $\mathrm{mg} / \mathrm{mL}$ nanoparticle suspension $(400 \mathrm{~mL})$ was added to the above pulp suspension. All the pulp fibers were kept immersed in the water. Then the vacuum was slowly removed and the suspension was stirred at a rate of $1000 \mathrm{rpm}$ for $1 \mathrm{~h}$, after which PEI was added and the suspension was continuously stirred at a rate of $300 \mathrm{rpm}$ for $4 \mathrm{~h}$. Subsequent treatment was the same as the conventional "lumen-loading" method.

\section{Detection and Characterization}

Magnetic nanoparticles were observed by transmission electron microscope (TEM, JEM-1230, JEOL Company). The black powder of magnetic nanoparticles was purified by ethanol washing and dried under vacuum. The product was used for X-ray diffraction analysis (ARL 9900 Series, Co K $\alpha$ ). The morphology of magnetic nanocomposite materials was analyzed by scanning electron microscope (SEM, Quanta-200, the Netherlands Fei company). Zeta potential was detected by Zeta potential analyzer (Beckman-Coulter Delsa 440sx). To determine the ash content, magnetic cellulose composites were first dried at $105{ }^{\circ} \mathrm{C}$ overnight and then ignited at $900{ }^{\circ} \mathrm{C}$ in a muffle furnace for $4 \mathrm{~h}$. Ash content was used as a measure of the lumen loading degree without a correction for the ash content of the fiber itself (typically $0.5 \%$ ash) or a very slight loss in the weight of the filler upon ignition. The hysteresis loops of samples were measured by a vibrating sample magnetometer (VSM, Lake Shore 7407) at room temperature. The physical properties of magnetic paper were tested following TAPPI method T494 om-01 (TAPPI 2001b). 


\section{RESULTS AND DISCUSSION}

\section{Magnetic Nanoparticles}

X-ray diffraction (XRD) was used to determine the crystal structure of magnetic nanoparticles, as seen in Fig. 1. In order to diminish the interference of background, Co $\mathrm{K} \alpha$ radiation was applied for these magnetic materials containing Fe element. The $d$ spacing is calculated from the electron diffraction equation,

$$
L \cdot \lambda=d \cdot R
$$

where $L$ is the distance between sample and electron micrograph, $\lambda$ is the X-ray wavelength, and $R$ is the radius of diffraction rings. Iron oxide possesses several possible structures such as magnetite $\left(\mathrm{Fe}_{3} \mathrm{O}_{4}\right)$, hematite $\left(\alpha-\mathrm{Fe}_{2} \mathrm{O}_{3}\right)$, maghemite $\left(\gamma-\mathrm{Fe}_{2} \mathrm{O}_{3}\right)$, or ferric hydroxide $(\beta-\mathrm{FeOOH})$. The $d$ spacing from X-ray diffraction (XRD) and selected area electron diffraction (SAED, Fig. 2) data are close to those of magnetite. This means that the main component of nanoparticles was $\mathrm{Fe}_{3} \mathrm{O}_{4}$ crystal (Zboril et al. 2002). The average particle crystallite size $D$ was calculated as ca. $15.2 \mathrm{~nm}$ from the Scherrer equation,

$$
D=K \cdot \lambda /(b \cdot \cos \theta)
$$

where $K$ is the Scherrer constant, $\lambda$ is the X-ray wavelength, $b$ is the peak width of halfmaximum, and $\theta$ is the Bragg diffraction angle. Details of structure are shown in Table 1.

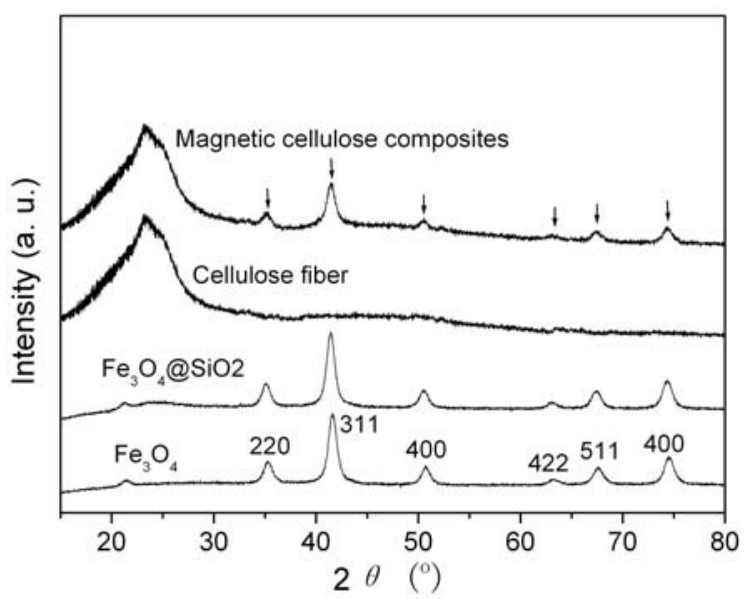

Fig. 1. XRD patterns of nanoparticles, cellulose fiber and composites. $\mathrm{Fe}_{3} \mathrm{O}_{4} @ \mathrm{SiO}_{2}$ : silica shell coated magnetite

Table 1. ED and XRD Data for the Magnetic Nanoparticles Prepared by Chemical Coprecipitation Method

\begin{tabular}{|c|c|c|c|c|c|c|c|}
\hline & 1 & 2 & 3 & 4 & 5 & 6 & 7 \\
\hline$R(\mathrm{~cm})$ & 0.70 & 1.15 & 1.36 & 1.63 & 1.98 & 2.10 & 2.31 \\
\hline ED results- $d(\AA)$ & 4.86 & 3.00 & 2.55 & 2.12 & 1.74 & 1.62 & 1.48 \\
\hline XRD results- $d(\AA)$ & 4.77 & 2.96 & 2.53 & 2.09 & 1.71 & 1.61 & 1.49 \\
\hline Theory values- $d(\AA) \mathrm{Fe}_{3} \mathrm{O}_{4}$ & 4.85 & 2.97 & 2.53 & 2.10 & 1.71 & 1.62 & 1.48 \\
\hline Crystalline plane $(\mathrm{hlk})$ & $(111)$ & $(220)$ & $(311)$ & $(400)$ & $(422)$ & $(511)$ & $(440)$ \\
\hline
\end{tabular}


Figure 2 shows TEM photographs of original magnetite and core-shell magnetite nanoparticles. Nanoparticles exhibit aggregates due to magnetism interaction. In principle, original $\mathrm{Fe}_{3} \mathrm{O}_{4}$ nanoparticles are uniform with an average diameter of $14.5 \mathrm{~nm}$, which is in good consistence with the result calculated from XRD. The magnetite crystals appeared as quasi-spherical nanoparticles (Fig. 2, A and B), a result that is related to the high nucleation speed during the precipitation. High-resolution TEM (HRTEM) images (Fig. 2, C and D) show clear crystal lattice, which is related to well crystallized magnetite. Particles oriented along different zone axis have been observed. The SAED pattern $(\mathrm{G})$ is indexed as a pure $\mathrm{Fe}_{3} \mathrm{O}_{4}$ phase of magnetite.



Fig. 2. TEM images of the magnetic nanoparticles. $\mathrm{Fe}_{3} \mathrm{O}_{4}(\mathrm{~A}, \mathrm{~B}, \mathrm{C}$ and $\mathrm{D}), \mathrm{HRTEM}$ micrographs of faceted nanocrystals (C and D); $\mathrm{Fe}_{3} \mathrm{O}_{4} @ \mathrm{SiO}_{2}(\mathrm{E}$ and $\mathrm{F})$. The SAED patterns(G) and $(\mathrm{H})$ are taken on nanoparticles in $(B)$ and $(F)$, respectively 
The synthesis of magnetic nanoparticles can be simply described as follows: There are both $\left[\mathrm{Fe}\left(\mathrm{H}_{2} \mathrm{O}\right)_{6}\right]^{2+}$ and $\left[\mathrm{Fe}\left(\mathrm{H}_{2} \mathrm{O}\right)_{6}\right]^{3+}$ during the coprecipitation process. At the mixing stage with $\mathrm{NH}_{3} \cdot \mathrm{H}_{2} \mathrm{O}$, the abrupt $\mathrm{pH}$ rise favors hydrolysis and promotes a burst nucleation of polymeric species (Cornell et al. 1989) derived from the two solvated iron cations, as the initial concentration is larger than the saturation level. The formation of magnetite embryo are favored at the presence of $\mathrm{Fe}(\mathrm{II})$ and $\mathrm{Fe}(\mathrm{III})$ in a 1:2 stoichiometric relationship, provoking a chain of the so-called olation and oxolation acid-base reactions (Kandori 2002). This is followed by a diffusion of Fe(III) ions octahedrally coordinated to the smaller tetrahedral site. The magnetite structure is preferably formed in preference to other iron oxides and oxyhydroxides because chains of centered $\mathrm{Fe}$ (II) and $\mathrm{Fe}$ (III) octahedra are predominantly formed, along the [100], which align parallel, two by two, and linked by $\mathrm{Fe}$ (III) at tetrahedral sites.

For core-shell $\mathrm{Fe}_{3} \mathrm{O}_{4}$ nanoparticles (Fig. 2, E and $\mathrm{F}$ ), the average diameter $(D)$ was about $115 \mathrm{~nm}$. There were several $\mathrm{Fe}_{3} \mathrm{O}_{4}$ cores encapsulated in each silica-modified nanoparticle. Most of them were observed to be independent core-shell structures without chain agglomeration. Similar SAED patterns (Fig. 2, G and $\mathrm{H}$ ) illustrate that $\mathrm{Fe}_{3} \mathrm{O}_{4}$ mainly remained unchanged after silica shell coating. What is more important is that separate distribution other than aggregates was observed for core-shell $\mathrm{Fe}_{3} \mathrm{O}_{4}$ nanoparticles. Here, silica shell stabilizes the magnetic nanoparticles in two different ways. One is sheltering the magnetic dipole interaction by increasing the distance between $\mathrm{Fe}_{3} \mathrm{O}_{4}$ cores. The magnetic dipole attraction in a simplified head to tail configuration is proportional to the $1 / r^{3}$ ( $r$ is the center distance of two dipoles). The attraction decreases quickly with an increase in the shell thickness (RocchiccioliDeltcheff et al. 1987). The other is bringing negative charge to the magnetic particles. The surface charge of $\mathrm{Fe}_{3} \mathrm{O}_{4}$ nanoparticles changes from $10.5 \mathrm{mV}$ to $-26.7 \mathrm{mV}$ after citric acid modification and further to $-39 \mathrm{mV}$ after silica modification. The final surface charge is close to that of silica nanoparticles $(-45 \mathrm{mV})$ (Michaela et al. 1999). So there is a repulsion effect between core-shell magnetite nanoparticles, which favors the formation of dispersive and stable colloidal suspension. In addition, silica shell modification can also prevent $\mathrm{Fe}_{3} \mathrm{O}_{4}$ core from oxidation (Wittmershaus et al. 2001).

\section{Magnetic Cellulose Composites}

For softwood kraft fiber, the hollow lumen usually has an inner diameter of more than ten microns. The volume of lumen is approximately 0.2 to $0.4 \mathrm{~cm}^{3} / \mathrm{g}$ of fiber (Satyanarayana and Wypych 2007). There are micropores and macropores with a size in the range of several to several hundred nanometers (Alince and van de Ven 1997). So it is feasible to realize lumen loading of nanoparticles. A theory for the kinetics of lumen loading has been presented by Zakaria et al. (2004b). In this paper, we put forward a modified "lumen-loading" process, in which vacuum was produced to enhance the entering of nanoparticles into the fiber lumen. The detailed loading process is shown in Fig. 3.

The change of color from the original white to brown indicates that magnetic nanoparticles successfully combined with cellulose fibers. XRD data offer further evidence (Fig. 1). The XRD pattern of magnetic cellulose composites is the integration of cellulose fiber and magnetic nanoparticles, in which characteristic peaks of both cellulose 
and $\mathrm{Fe}_{3} \mathrm{O}_{4} @ \mathrm{SiO}_{2}$ are observed. The result also indicates that the properties of magnetic nanoparticles did not change during the loading process.

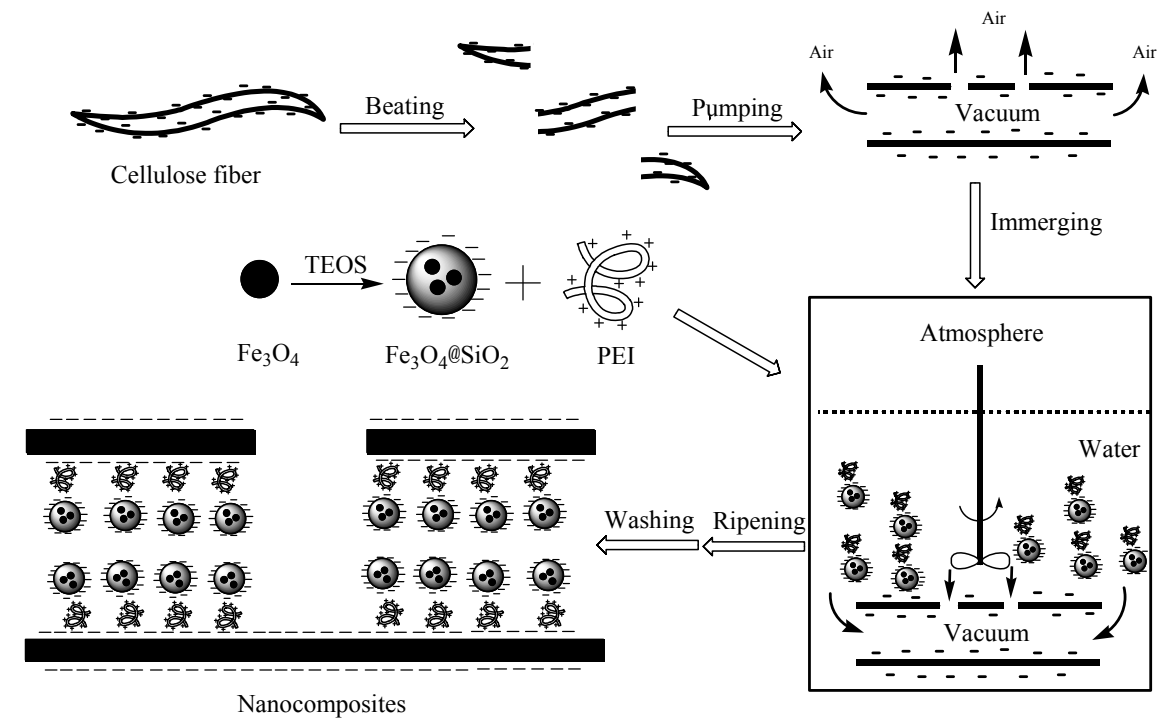

Fig. 3. "Vacuum-Lumen-loading" process of $\mathrm{Fe}_{3} \mathrm{O}_{4} @ \mathrm{SiO}_{2}$ nanoparticles

Figure 4 presents the SEM images of magnetic cellulose composites. After loading of magnetic nanoparticles, comparatively smooth surfaces of the original fiber became rough. No single nanoparticle but aggregates were found be the main deposition form. It could be speculated that magnetic dipole attractions led to the aggregation of nanoparticles during the loading and drying processes. There were a few nanoparticles loaded on the external surface of fiber. Most of them were loaded at disturbed sites (Fig. $4, \mathrm{C}$ ), such as crevices, twists, and breakages, etc. A sporadic distribution of deposition of nanoparticles was observed at other flat places. Besides the loading on the external surface of fiber, a large number of nanoparticles became encapsulated in the pores and lumen, especially in the transect area (Fig. 4, E-H). Unlike the analogous monolayer deposition on the exterior, there were multilayer depositions of nanoparticles in pores and lumen. The difference in the distribution at different areas of fiber is reasonable, considering the preparation process of composites. As seen in Fig. 3, stirring is necessary during the loading process in order to produce turbulent flow in the container and increase the number of nanoparticles penetrating into the fiber pores and lumen. The direct effect is that magnetic nanoparticles loosely attached on the external surface may fall off under the fluid shearing force. On the other hand, nanoparticles encapsulated in the lumen are protected from the shearing force by the cell wall. In addition, a rinsing process was conducted followed the ripening. This process can further wash away some nanoparticles loaded on the exterior surface, especially those at the relatively flat areas. In principle, ideal cellulose fiber magnetic composites are designed to incorporate the nanoparticles in the lumen and preserve the bare external surface of original fiber. The main purpose is to make full use of the exposed cellulose on the exterior without influences on the optimization of magnetism. Exposed cellulose is crucial for the hydrogen-bond combination and paper strength. Chemical modification, such as oxidation, coupling, grafting, etc., can also be conducted for further applications. 


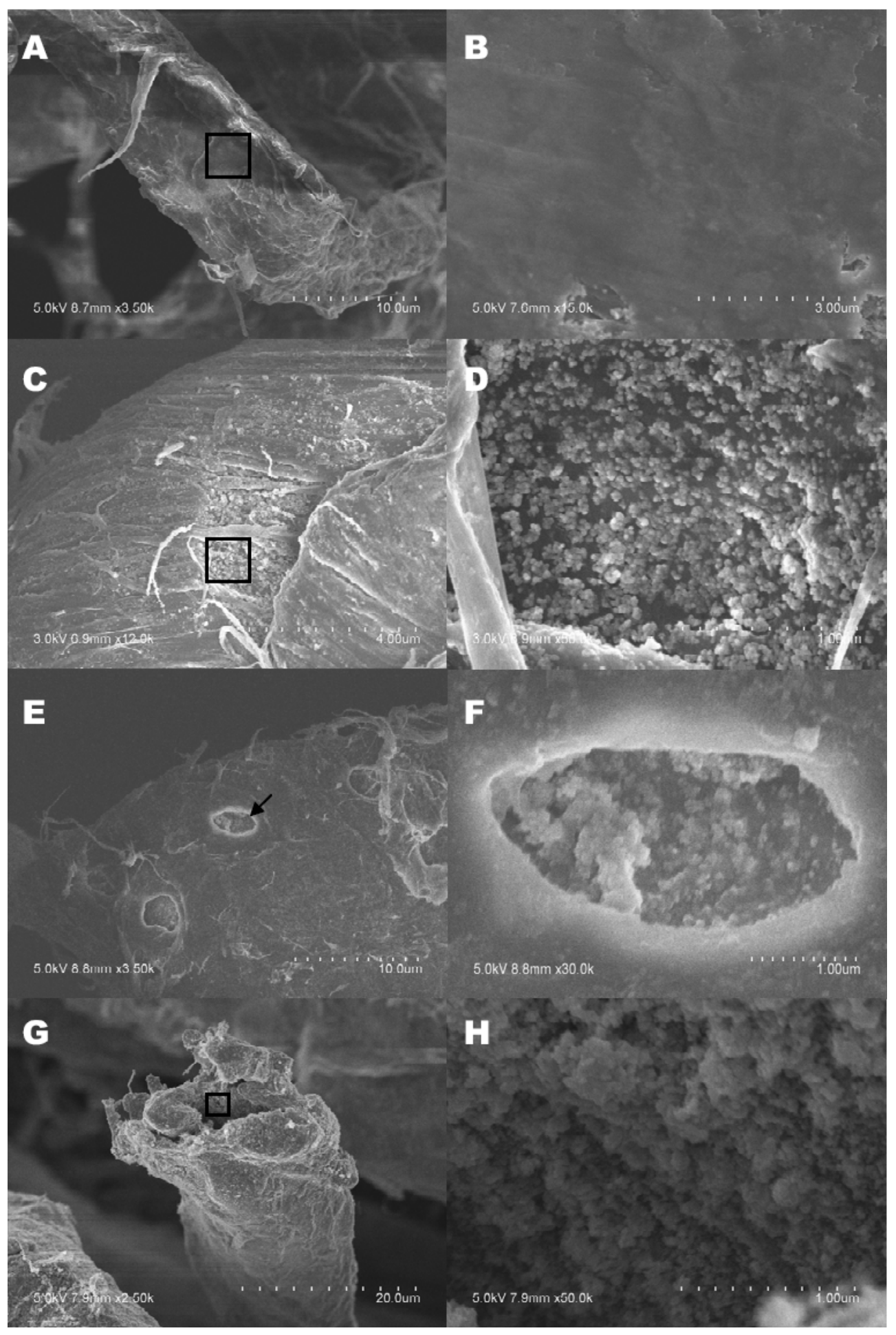

Fig. 4. SEM images of magnetic composites. Original cellulose fiber (A); Cellulose fiber/ $\mathrm{Fe}_{3} \mathrm{O}_{4} @ \mathrm{SiO}_{2}$ composites: external surface (C), pore (E), transverse section (G). B, D, F, and H are magnifications of selected regions 
Magnetic susceptibility, which is determined by the level of loaded magnetic nanoparticles (Mancosky and Lucia 2005), is also important. Three means were applied to increase the amount of nanoparticles encapsulated in the lumen. The first is moderate pulp beating. Beating can result in more channels connecting interior and exterior as well as increased internal surface area. It can also remove the pit or pore membranes, which obstruct filler entry into the lumen. All the changes are favorable to increase the chance and capacity of holding nanoparticles in the lumen. The second is silica shell coating on magnetite. As discussed above, aggregates of nanoparticles are greatly reduced after silica modification. So it is much easier for them to penetrate into the lumen through the macropores and transects of fiber. In addition, PEI, a cationic polyelectrolyte having high charge density, was used as retention aid to provide bridge linking between fiber and nanoparticles. After silica shell modification, $\mathrm{Fe}_{3} \mathrm{O}_{4} @ \mathrm{SiO}_{2}$ possesses a negatively charged surface. So the interaction between electronegative fiber and $\mathrm{Fe}_{3} \mathrm{O}_{4} @ \mathrm{SiO}_{2}$ was strengthened through the connection of positive PEI, as seen in Fig. 3. The last is the application of vacuum during the loading process. The differential pressure inside and outside enhances the encapsulation of nanoparticles in the fiber lumen. During the "vacuum-lumen-loading" process, open and hollow fibers are necessary to realize efficient penetration and encapsulation of nanoparticles in the lumen. It is known that cellulose fiber will collapse using normal drying methods because of the big surface tension between water and cellulose. In the present work, vacuum freezing drying technology was used to keep the shape and structure of fiber after swelling and beating. Detailed loading data under different conditions are shown in Table 2. It can be seen that all the three means applied were favorable to increase the loading degree of magnetic nanoparticles. Above all, the originally designed idea was realized to a great extent based on the findings and results.

\section{Physical Properties of Magnetic Paper Sheet}

The effects of beating degree, PEI dosage and molecular weight $\left(M_{\mathrm{PEI}}\right)$ on the loading degree and physical properties of magnetic paper were studied, as listed in Table 2. Compared with base paper (BP-1), magnetic paper (MP-2) was found to have decreased physical strength of the paper sheet. The physical strength generally dropped when loading degree increased. The change may be caused by the following two reasons: First, there was unavoidable deposition of nanoparticles on the external surface blocks the effective contact of the fibers; Second, the relative bonded area between fibers was reduced since fiber became more erect and stiff after lumen loading (Kumar et al. 2009).

The effect of beating degree on the paper strength was similar to that on the loading degree, which has been discussed in above section. The difference is that paper strength dropped slightly when beating degree was higher than $24^{\circ} \mathrm{SR}$. As we know, beating can increase the area of hydrogen-bond combination, while excessive beating is not favorable, because of too much cutting of fibers. In addition, beating also leads to an increase in the external surface area of fiber, which favors the unexpected deposition of nanoparticles on the exterior of fiber. So beating degree should be controlled properly. 
Table 2. Details of Magnetic Paper Sheets

\begin{tabular}{|c|c|c|c|c|c|c|c|}
\hline Sample & Filler & $\begin{array}{l}B D \\
\text { ( } \mathrm{O} \text { (SR) }\end{array}$ & $\begin{array}{c}D_{\mathrm{PEI}} \\
(\mathrm{wt} \%)^{*}\end{array}$ & $M_{\mathrm{PEI}}$ & $\begin{array}{c}L D \\
(w t \%)^{*}\end{array}$ & $\begin{array}{c}B I \\
\left(\mathrm{kPa} \cdot \mathrm{m}^{2} / \mathrm{g}\right)\end{array}$ & $\begin{array}{c}\mathrm{TI} \\
(\mathrm{Nm} / \mathrm{g})\end{array}$ \\
\hline BP-1 & - & 9 & - & - & - & 2.8 & 42.9 \\
\hline MP-2 & $\mathrm{Fe}_{3} \mathrm{O}_{4}$ & 15 & 2 & 3000 & 6.9 & 1.6 & 24.3 \\
\hline MP-3 & $\mathrm{Fe}_{3} \mathrm{O}_{4}$ & 24 & 2 & 3000 & 7.6 & 2.0 & 29.4 \\
\hline MP-4 & $\mathrm{Fe}_{3} \mathrm{O}_{4}$ & 31 & 2 & 3000 & 8.5 & 1.7 & 27.6 \\
\hline MP-5 & $\mathrm{Fe}_{3} \mathrm{O}_{4} @ \mathrm{SiO}_{2}$ & 9 & 2 & 3000 & 5.1 & 0.6 & 11.5 \\
\hline MP-6 & $\mathrm{Fe}_{3} \mathrm{O}_{4} @ \mathrm{SiO}_{2}$ & 15 & 0 & 3000 & 2.1 & 2.9 & 46.3 \\
\hline MP-7 & $\mathrm{Fe}_{3} \mathrm{O}_{4} @ \mathrm{SiO}_{2}$ & 15 & 1 & 3000 & 7.0 & 1.9 & 32.6 \\
\hline MP-8 & $\mathrm{Fe}_{3} \mathrm{O}_{4} @ \mathrm{SiO}_{2}$ & 15 & 2 & 3000 & 10.1 & 1.2 & 21.0 \\
\hline MP-9 & $\mathrm{Fe}_{3} \mathrm{O}_{4} @ \mathrm{SiO}_{2}$ & 15 & 3 & 3000 & 7.5 & 1.7 & 25.7 \\
\hline MP-10 & $\mathrm{Fe}_{3} \mathrm{O}_{4} @ \mathrm{SiO}_{2}$ & 15 & 4 & 3000 & 5.3 & 2.3 & 34.8 \\
\hline MP-11 & $\mathrm{Fe}_{3} \mathrm{O}_{4} @ \mathrm{SiO}_{2}$ & 24 & 2 & 1000 & 9.7 & 2.7 & 37.1 \\
\hline MP-12 & $\mathrm{Fe}_{3} \mathrm{O}_{4} @ \mathrm{SiO}_{2}$ & 24 & 2 & 3000 & 11.7 & 2.5 & 33.4 \\
\hline MP-13 & $\mathrm{Fe}_{3} \mathrm{O}_{4} @ \mathrm{SiO}_{2}$ & 24 & 2 & 5000 & 13.2 & 2.4 & 34.0 \\
\hline MP-14 & $\mathrm{Fe}_{3} \mathrm{O}_{4} @ \mathrm{SiO}_{2}$ & 31 & 2 & 3000 & 11.9 & 1.8 & 25.8 \\
\hline VMP-15 & $\mathrm{Fe}_{3} \mathrm{O}_{4} @ \mathrm{SiO}_{2}$ & 15 & 2 & 3000 & 13.4 & 0.7 & 11.3 \\
\hline VMP-16 & $\mathrm{Fe}_{3} \mathrm{O}_{4} @ \mathrm{SiO}_{2}$ & 24 & 2 & 3000 & 14.3 & 1.0 & 17.7 \\
\hline VMP-17 & $\mathrm{Fe}_{3} \mathrm{O}_{4} @ \mathrm{SiO}_{2}$ & 31 & 2 & 3000 & 15.5 & 0.8 & 14.0 \\
\hline
\end{tabular}

PEI is another critically important factor (Petlicki et al. 1994; van de Ven 1994). For MP-4, MP-5, MP-6, and MP-7, maximum loading degree was reached at a PEI dosage of $2 \mathrm{wt} \%$. On the contrary, further addition of PEI decreased the loading degree. Excessive PEI can change both fibers and $\mathrm{Fe}_{3} \mathrm{O}_{4} @ \mathrm{SiO}_{2}$ from negative to positive net charge. Under this circumstance, positive nanoparticles will repel the positive lumen wall. Thus, an excessive dosage of PEI would play a role of dispersant that prevents the deposition of nanoparticles more than a retention aid. PEI may play another role of strengthen aid (Wei et al. 2009). So it is reasonable that the physical property of paper sheet is improved with an increase in PEI dosage (Tang et al. 2008). PEI with low molecular weight was found to give a comparatively low loading degree of nanoparticles. The effect of molecular weight on the loading degree is not clear for the moment. The reason may be that higher-mass PEI provides sufficiently large positively charged "patches" on the surfaces to allow more effective electrostatic attraction between nanoparticles and fibers, while lower-mass PEI becomes less effective because of facile permeation into cell wall.

\section{Magnetic Properties of Nanoparticles and Composites}

Figure 5 illustrates the hysteresis loops of magnetic nanoparticles and composites under the same condition. All the prepared samples showed superparamagnetic characteristics that were greatly different from bulk $\mathrm{Fe}_{3} \mathrm{O}_{4}$ materials. The saturation magnetization $\left(M_{\mathrm{s}}\right)$ of $\mathrm{Fe}_{3} \mathrm{O}_{4}$ nanoparticles was $47.99 \mathrm{emu} / \mathrm{g}$, which agrees well with that of magnetite 
by reduction coprecipitation method (Sato et al. 1987). Since the introduction of silica shell reduces the content of magnetic materials, $M_{\mathrm{s}}$ drops from $47.99 \mathrm{emu} / \mathrm{g}$ to 20.56 emu/g. However, the $M_{\mathrm{s}}$ of cellulose fiber $/ \mathrm{Fe}_{3} \mathrm{O}_{4} @ \mathrm{SiO}_{2}$ composites is comparative to that of cellulose fiber $/ \mathrm{Fe}_{3} \mathrm{O}_{4}$ composites. The reason can be attributed to the higher loading degree and better distribution of magnetic nanoparticles in composites. No visible remnant magnetization $\left(M_{\mathrm{r}}\right)$ and coercivity $\left(H_{\mathrm{c}}\right)$ were observed for nanoparticles. It has been reported that nanoparticles smaller than the critical size of $166 \mathrm{~nm}$ possess superparamagnetism (O'Hnadley et al. 2000). The apparent small $H_{\mathrm{c}}$ of $\mathrm{Fe}_{3} \mathrm{O}_{4} @ \mathrm{SiO}_{2}$ nanoparticles is mainly caused by the pinning effect of silica shell that hinders the change of magnetic moment (Jian et al. 2004).

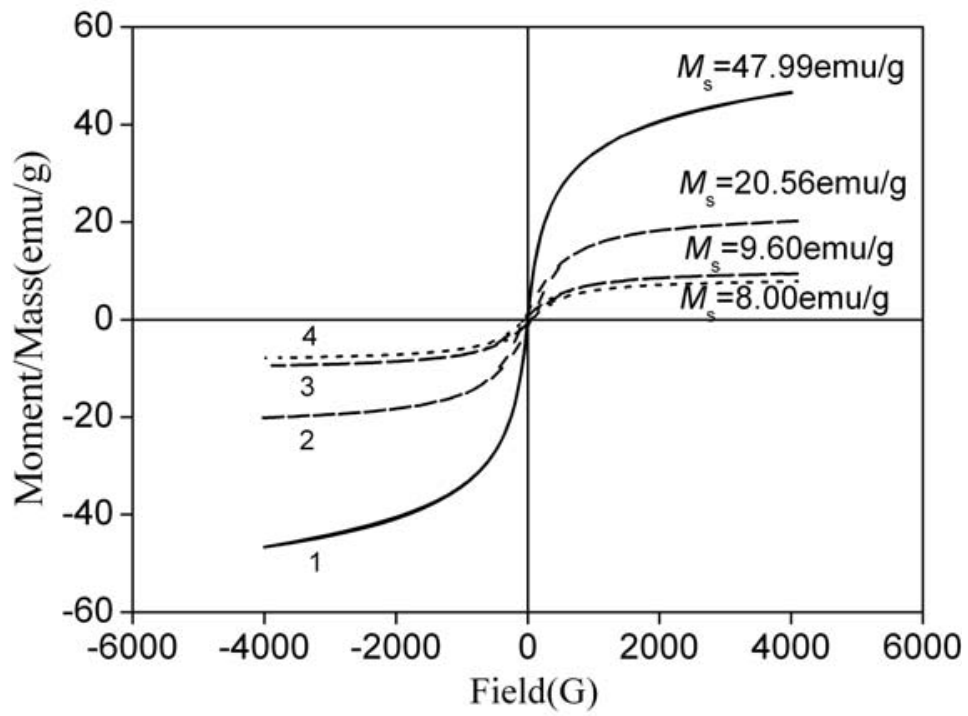

Fig. 5. Hysteresis loops of magnetic nanoparticles and paper at room temperature. $\mathrm{Fe}_{3} \mathrm{O}_{4}$ (1); $\mathrm{Fe}_{3} \mathrm{O}_{4} @ \mathrm{SiO}_{2}(2) ; \mathrm{MP}-13$ (3); MP-9 (4)

\section{CONCLUSIONS}

1. Magnetic cellulose fiber $/ \mathrm{Fe}_{3} \mathrm{O}_{4} @ \mathrm{SiO}_{2}$ composites were prepared by a "vacuumlumen-loading" method with PEI as retention aid. The magnetic composites were further made into paper sheets.

2. $\mathrm{Fe}_{3} \mathrm{O}_{4} @ \mathrm{SiO}_{2}$ nanoparticles showed positive electrical charge and could be dispersed in water suspension. Magnetic composites were found to be deposited as nanoparticles on the exterior, in the pores, and especially in the lumens of fibers. Pulp beating, silica shell modification of magnetite, vacuum application, and PEI dosing were found to be favorable to the lumen loading of nanoparticles.

3. Nanoparticle deposition on exterior surfaces blocked hydrogen-bonding between fibers to some extent and led to a decrease in the physical strength of magnetic paper. Both the cellulose fiber composites and paper possessed good superparamagnetism with negligible $M_{\mathrm{r}}$ and $H_{\mathrm{c}}$. Such materials will enable potential application in electromagnetic shielding, magnetographic printing, and magnetic filtering. 


\section{ACKNOWLEDGMENTS}

The authors are thankful to the key Laboratory of Molecular and Biomolecular Electronics, Southeast University. The support of this work by National Natural Science Foundation of China (No. 30972321), State Key Lab of Pulp and Paper Engineering of china (No. 201019), and Basic Research Project of Natural Science Foundation of Jiangsu Provincial Universities (No. 10KJB53007) is gratefully acknowledged.

\section{REFERENCES CITED}

Alince, B., and van de Ven, T. G. M. (1997). "Porosity and swollen pulp fibers evaluated by polymer adsorption," In C. F. Baker (ed.), Fundamentals of Papermaking Materials, Trans. 11th Fundamental Research Symposium, Pira Intl., Leatherhead, Surry, UK, 771-788.

Berger, P., Adelman, N. B., Beckman, K. J., Campbell, D. J., Ellis, A. B., and Lisensky, G. C. (1999). "Preparation and properties of an aqueous based ferrofluid," J. Chem. Ed. 76(7), 943-948.

Bakirtzis, D., Delichatsios, M. A., Liodakis, S., and Ahmed, W. (2009). "Fire retardancy impact of sodium bicarbonate on ligno-cellulosic materials," Thermochim. Acta 486(1-2), 11-19.

Basta, A. H., Fadl, N. A., and Abd-El-Messieh, S. L. (2002). "Properties of paper sheets prepared from in-situ synthesis of cuprite in wood pulp fibers," Int. J. Polym. Mater. 51, 325-349.

Carrazana-Garcia, J. A., Lopez-Quintela, M. A., and Rivas- Rey, J. (1995). "Ferrimagnetic paper obtained by in situ synthesis of substituted ferrites," IEEE Trans. Magn. 31(6), 3126-3130.

Carrazana-Garcia, J. A., Lopez-Quintela, M. A., and Rivas- Rey, J. (1997). "Characterization of ferrite particles synthesized in presence of cellulose fibers," Colloids Surf. A: Physicochem. Eng. Aspects 121(1), 61-66.

Chia, C. H., Zakariaa, S., Nguyenb, K. L., and Abdullaha, M. (2008). "Utilisation of unbleached kenaf fibers for the preparation of magnetic paper," Ind. Crop. Prod. 28, 333-339

Cornell, R. M., Giovanoli, R., and Schneider, W. (1989). "Review of the hydrolysis of iron(III) and the crystallization of amorphous iron(III) hydroxide hydrate," J. Chem. Technol. Biotechnol. 46(2), 115-134.

Eriksson, M., Notley, S., and Wågberg, L. (2005). "The influence on paper strength properties when building multilayers of weak polyelectrolytes onto wood fibres," $J$. Colloids Interface Sci. 292, 38-45

Fukahori, S., Iguchi,Y., Ichiura, H., Kitaoka, T., Tanaka, H., and Wariishi, H. (2007). "Effect of void structure of photocatalyst paper on VOC decomposition," Chemosphere 66, 2136-2141.

Jian, J., Shin-ichi, O., and Kazuhito, H. (2004). "Giant coercive field of nanometer- sized iron oxide," Adv. Mater. 16(1), 48-51. 
Johnston, H., Kelly, F. M., Moraes, J., Borrmann, T., and Flynn, D. (2006). “Conductive polymer composites with cellulose and protein fibres," Curr. Appl. Phys. 6(3), 587590.

Kandori, K. (2002). "Iron oxide particles,” In: Encyclopedia of Surface and Colloid Science, Marcel Dekker Inc, New York.

Khan, M. K., and Sundararajan, P. (2011). "Encapsulation of dye molecules and nanoparticles in hollow organogelfibers of a nonchiral polyurethane model compound," Chem. Eur. J. 17, 1184-1192.

Kumar, P., Gautam, S. K., Kumar, V., and Singh, S. P. (2009). "Enhancement of optical properties of bagasse pulp by in-situ filler precipitation," BioResources 4(4), 1635 1646.

Kumar, P., Negi, Y. S., and Singh, S. P. (2011). "Filler loading in the lumen or/and cell wall of fibers - A literature review," BioResources 6(3), 3526-3546.

Marchessault, R. H., Rioux,P., and Raymond, L. (1992). "Magnetic cellulose fibers and paper: Preparation, processing and properties," Polymer 33(19), 4024-4028.

Mancosky, D. G., and Lucia, L. A. (2005). "A novel and efficient approach for imparting magnetic susceptibility to lignocellulosic fibers," Carbohydr. Polym. 59, 517-520.

Middleton, S. R., and Scallan, A. M. (1985). "Lumen-loaded paper pulp: Mechanism of filler-to-fiber bonding," Colloid. Surf. 16, 309-322.

Michaela, K., Andre, A., and Christian, G. (1999). "Silica coating on colloidal maghemite particles," J. Colloid Interface Sci. 220(2), 357-361.

Middleton, S. R., and Scallan, A. M. (1989). "The effect of cationic starch on the tensile strength of paper," J. Pulp Pap. Sci. 15(5), J229-J234.

O’Handley, R. C. (2000). Modern Magnetic Materials - Principles and Applications, John Wiley \& Sons, New York.

Petlicki, J., and van de Ven, T. G. M. (1994). "Adsorption of polyethylenimine onto cellulose fibers," Colloids Surf. A: Physicochem. Eng. Aspects 83(1-2), 9-23.

Qian, L., Guan, Y., Ziaee, Z., He, B., Zheng, A., and Xiao, H. (2009). "Rendering cellulose fibers antimicrobial using cationic beta-cyclodextrin-based polymers included with antibiotics," Cellulose 16(2), 309-317.

Raymond, L., Revol, J. F., Ryan, D. H., and Marchessault, R. H. (1994). "In situ synthesis of ferrites in cellulosics In situ synthesis of ferrites in cellulosics," Chem. Mater. 6(2), 249-255.

Rocchiccioli-Deltcheff, C., Franck, R., Cabuil, V., and Massart, R. (1987). "Surfacted ferrofluid: interactions at the magnetic iron oxide interface," J. Chem. Res.(s), 5, 126127.

Roy, D., Knapp, J. S., Guthrie, J. T., and Perrier, S. (2008). “Antibacterial cellulose fiber via RAFT surface graft polymerization,” Biomacromolecules 9(1), 91-99.

Sarrazin, P., Valecce, L., Beneventi, D., Chaussy, D., Vurth, L., and Stephan, O. (2007). "Photoluminescent paper based on poly(fluorene-co-fluorenone) particles adsorption on modified cellulose fibers," Adv. Mater. 19(20), 3291-3294.

Sato, T., Iijima, T., Sekin, M., and Inagaki, N. (1987). "Magnetic properties of ultrafine ferrite particles," J. Magn. Magn. Mater. 65, 252-256 
Satyanarayana, K. G., and Wypych, F. (2007). "Characterization of natural fibers," In: Handbook of Engineering Biopolymers: Homopolymers, Blends and Composites, Fakirov, S., and Bhattacharyya, D. (eds.), 3-48.

Shen, J., Song, Z. Q., Qian, X. R., and Ni, Y. H. (2011). "A review on use of fillers in cellulosic paper for functional applications," Ind. Eng. Chem. Res. 50(2), 661-666.

Small, A. C., and Johnston, J. H. (2009). "Novel hybrid materials of magnetic nanoparticles and cellulose fibers," J. Colloid Interface Sci. 331(1), 122-126.

Suber, L., Foglia, S., and Ingo, G. M. (2001). "Synthesis, and structural and morphological characterization of iron oxide-ion-exchange resin and-cellulose composites," Appl. Organometal. Chem. 15(5), 414-420.

Sun, Y., Duan, L., Guo, Z., Duan, M. Y., Ma, M., Xu, L., Zhang, Y., and Gu, N. (2005). "An improved way to prepare superparamagnetic magnetite silica core-shell nanoparticles for possible biological application,” J. Magn. Magn. Mater. 285(1-2), 65-70.

Tang, A. M., Wang, X., Cheng, G., and Zhang, H. W. (2008). "Study on characteristics of In-situ composition of nature kapok fibers/magnetic nano-particles," Chinese J. Mater. Eng. (10), 80-85.

TAPPI (2001a). " Laboratory beating of pulp (Valley beater method)," T200 sp-02.

TAPPI (2001b). "Tensile properties of paper and paperboard (using constant rate of elongation apparatus)," T494 om-1.

TAPPI (2002). "Forming handsheets for physical tests of pulp," T205 sp-02.

van de Ven, T. G. M. (1994). "Kinetic aspects of polymer and polyelectrolyte adsorption on surfaces," Adv. Colloid Interface Sci. 48, 121-140.

Wei, J. F., Li, X. R., and Li, G. H. (2009). "Modified polyethylene imine with epoxy resin emulsion as papermaking strength agent," Trans. China Pulp Pap. (1), 81-84.

Wittmershaus, B. P., Skibicki, J. J., McLafferty, J. B., Zhang, Y. Z., and Swan, S. (2001). "Spectral properties of single BODIPY dyes in polystyrene microspheres and in solutions," J. Fluor. 11(2), 119-128.

Zakaria, S., Ong, B. H., and van de Ven, T. G. M. (2004a). "Lumen loading magnetic paper I : Flocculation,” Colloids Surf. A: Physicochem. Eng. Aspects 251(1), 1-4.

Zakaria, S., Ong, B. H., and van de Ven, T. G. M. (2004b). "Lumen loading magnetic paper II : mechanism and kinetics," Colloids Surf. A: Physicochem. Eng. Aspects 251(1), 31-36.

Zboril, R., Mashlan, M., and Petridis, D. (2002). "Iron(III) oxides from thermal processes-synthesis, structural and magnetic properties, Mossbauer spectroscopy characterizationand applications," Chem. Mater.14(3), 969-982.

Zheng, Z., McDonald, J., Khillan, R., Shutava, T., Grozdits, G., and Lvov, Y. (2006). "Layer-by-layer nanocoating of lignocellulose fibers for enhanced paper properties," J. Nanosci. Nanotechnol. 6(3), 624-632.

Article submitted: June 28, 2011; Peer review completed: July 18, 2011; Revised version received and accepted: July 19, 2011; Published: July 20, 2011. 